\title{
AVALIAÇÃO DA ATIVIDADE ANTIOXIDANTE DO ÁCIDO FÍTICO DE GERME DE MILHO
}

\author{
Cristina Tostes Filgueiras, Adriana Lourenço Soares, Massami Shimokomaki e Elza Iouko Ida* \\ Departamento de Ciência e Tecnologia de Alimentos, Universidade Estadual de Londrina, CP 6001, 86051-990 Londrina - PR, Brasil \\ Rúbia Casagrande \\ Departamento de Ciências Farmacêuticas, Universidade Estadual de Londrina, CP 6001, 86051-990 Londrina - PR, Brasil
}

Recebido em 12/8/08; aceito em 26/3/09; publicado na web em 4/8/09

\begin{abstract}
CORN GERM PHYTIC ACID ANTIOXIDANT ACTIVITY EVALUATION. The obtained corn germ phytic acid (CGPA) antioxidant potential was evaluated through the deoxyribose, bathophenanthroline (BPS) and DPPH'assays. In the concentration of $130.5 \mu \mathrm{M}$ of CGPA the hydroxyl radical maximum sequestering antioxidant activity was $29.3 \%$ while standard phytic acid (SPA) presented this maximum activity of $18.2 \%$ in the concentration of $33.2 \mu \mathrm{M}$ of SPA. The BPS assays revealed that the chelation activity towards $\mathrm{Fe}^{2+}$ increased concurrently with the increase of CGPA concentration and its $\mathrm{Fe}^{2+}$ contact time. Finally, DPPH${ }^{*}$ assay showed that CGPA and SPA did not present electron-donating capacity to DPPH:
\end{abstract}

Keywords: phytic acid; antioxidant; corn germ.

\section{INTRODUÇÃ̃o}

O ácido fítico (AF) ou mio-inositol hexafosfato (IP6) está presente em cereais, leguminosas, oleaginosas, pólens e amêndoas, em concentrações variando de 1 a $5 \%$ do seu peso. ${ }^{1}$ Nos cereais, o AF está distribuído em diferentes componentes do grão. A maior concentração do AF no trigo está na aleurona e, no arroz, no pericarpo, enquanto que o milho apresenta elevado teor no germe e ao redor de $6,5 \% .^{2-5}$

$\mathrm{O}$ AF apresenta cargas negativas em ampla faixa de $\mathrm{pH}$ e possui 12 hidrogênios dissociáveis. ${ }^{6}$ Estas características proporcionam ao AF uma propriedade quelante com metais polivalentes, especialmente cátions di e trivalentes, formando complexos. ${ }^{7}$ Devido à propriedade quelante e formação de complexos com alguns minerais importantes, tornando-os bioindisponíveis, muitas investigações foram desenvolvidas considerando-se o AF como um antinutriente. ${ }^{1}$ Entretanto, a bioindisponibilidade depende de fatores experimentais como proporção metal:fitato ${ }^{8}$ e tipo de dieta. ${ }^{9}$ Por outro lado, a propriedade quelante do AF é de elevada importância devido a sua ação como um antioxidante e anticancerígeno. ${ }^{8,10-13}$ A habilidade do AF formar um quelato com o ferro, que o torna cataliticamente inativo, confere ao AF uma atuação como um antioxidante, pois inibe a oxidação com formação de radicais hidroxil $(\bullet \mathrm{OH}) .^{10,14-16}$

Estudos in vitro indicaram que o AF e seus derivados, o inositol pentafosfato (IP5), inositol tetrafosfato (IP4) e inositol trifosfato (IP3) apresentam capacidade de ligação aos íons metálicos dependendo do número de fosfatos desprotonados da molécula. ${ }^{17}$

A propriedade antioxidante ou quelante do AF torna-o um composto único e versátil como aditivo de alimentos ${ }^{18}$ e rotineiramente empregado em vários países para prevenir a descoloração, melhorar a qualidade nutricional e prolongar a validade dos produtos. ${ }^{19} \mathrm{O} \mathrm{AF}$ foi reconhecido em 1997 como GRAS (Generally Recognised as Safe) pela FDA (Food and Drug Administration) e tem sido usado como um aditivo em produtos de panificação. ${ }^{20}$ No Codex Alimentarius, o AF foi revisado como antioxidante com INS (System for Food Additives) número 391.21

O potencial antioxidante do AF foi confirmado por vários autores, principalmente em produtos cárneos ou sistemas modelos ${ }^{10,12,13,19,22-24}$ com finalidade de preservar o produto. Entretanto, não há descrições

*e-mail: elida@uel.br na literatura sobre o mecanismo de ação do AF como antioxidante por meio de ensaios específicos.

Vários métodos foram desenvolvidos para determinar a capacidade antioxidante. ${ }^{25,26}$ Dentre estes métodos destacam-se o sistema de quelar íons $\mathrm{Fe}^{+2}$ usando a batofenantrolina (BPS) e os métodos de sequestro de radicais livres, tais como $\mathrm{DPPH}^{\bullet}$ (2,2-difenil-1-picrilhidrazil) e radical hidroxil por meio do ensaio de deoxirribose. ${ }^{26}$

O método para determinação da atividade queladora do íon ferro pelo antioxidante, utilizando a BPS como um forte quelador de ferro, baseia-se na formação do complexo colorido $\mathrm{Fe}_{2}(\mathrm{BPS})_{3}$, o qual pode ser alterado pela maior ou menor afinidade do antioxidante pelo ferro. ${ }^{27} \mathrm{O}$ método para avaliar o sequestro de radicais livres está baseado na capacidade de compostos doarem elétrons ao radical estável DPPH ${ }^{\cdot 28,29}$ e o ensaio de deoxirribose avalia a eficiência do antioxidante no sequestro de radicais hidroxil. ${ }^{30}$ No ensaio de deoxirribose, o açúcar é degradado na presença de radical hidroxil gerado pela mistura de $\mathrm{Fe}^{3+}$, ascorbato, $\mathrm{H}_{2} \mathrm{O}_{2}$ e EDTA. Os radicais hidroxil ao reagirem com a deoxirribose resultam em uma série de reações formando substâncias reativas ao ácido tiobarbitúrico e avaliadas como malonaldeído (MDA). O MDA pode ser detectado pela sua capacidade de reagir com o ácido tiobarbitúrico (TBA) em condições ácidas. ${ }^{30,31}$ Qualquer outra molécula, adicionada à mistura de reação, com capacidade de reagir com radical hidroxil pode competir com a deoxirribose por este radical, acarretando, portanto, num decréscimo da taxa de degradação de deoxirribose. ${ }^{32}$

Considerando a atuação do AF como antioxidante, suas várias aplicações e elevada concentração no germe de milho, este trabalho avaliou o potencial antioxidante do AF obtido do germe por meio de ensaios de deoxirribose, batofenantrolina e DPPH'.

\section{PARTE EXPERIMENTAL}

\section{Material}

Para obtenção de AF foi utilizado germe de milho desengordurado, que foi fornecido por uma Cooperativa Agrícola da região. O material continha 4,8\% de AF que foi extraído com $\mathrm{HCl}$ 0,8M (1:5 $\mathrm{p} / \mathrm{v})$, seguido de centrifugação, etapas de precipitação e secagem. ${ }^{33}$ O rendimento da obtenção foi de $67,0 \%$ e pureza de $85,4 \%$ e o AF assim obtido foi denominado como AF-GM e quantificado por 
cromatografia de troca iônica e espectrofotometria a $500 \mathrm{~nm}^{34}$ com modificação da resina para DOWEX-AGX-4. ${ }^{35} \mathrm{O}$ AF padrão utilizado foi o fitato de dodecassódio $\left(\mathrm{Na}_{12} \mathrm{C}_{6} \mathrm{H}_{6} \mathrm{O}_{24} \mathrm{P}_{6} ; \mathrm{PM}=923,8\right)$ de milho, com $90 \%$ de pureza, da Sigma.

\section{Preparo das amostras}

O AF-GM e AF padrão, em triplicatas, foram diluídos em água deionizada com obtenção de concentrações finais de 0,$3 ; 0,6 ; 1,3$; 2,$6 ; 3,3 ; 6,6 ; 13,1 ; 16,6 ; 33,2 ; 66,5 ; 130,5 ; 261,87$ e $652,7 \mu \mathrm{M}$ e empregadas para investigar o potencial antioxidante por meio de ensaios utilizando $\mathrm{DPPH}^{\circ}$, deoxirribose e batofenantrolina.

\section{Precisão dos métodos analíticos}

A precisão dos métodos de deoxirribose e batofenantrolina foi determinada pela repetibilidade (intraensaio) e precisão intermediária (interensaio). A repetibilidade, para o ensaio de deoxirribose, foi avaliada no mesmo dia por meio de análises de amostras com a mesma concentração (6,6 e 66,5 $\mu \mathrm{M}$ de AF padrão). Para ensaio de batofenantrolina foram utilizadas concentrações de 3,3 e 6,6 $\mu \mathrm{M}$ de AF padrão. A precisão intermediária foi determinada nas mesmas concentrações e comparadas as análises em 3 dias diferentes.

\section{Ensaio de DPPH*}

A atividade antioxidante de diferentes concentrações de AF padrão e AF-GM foi determinada pela capacidade doadora de elétrons do AF ao radical livre estável DPPH' (2,2-difenil-1-picril-hidrazil). ${ }^{36}$ Foram misturados em tubos de ensaio $1 \mathrm{~mL}$ de tampão acetato 100 $\mathrm{mM}$, pH igual a 5,5, $1 \mathrm{~mL}$ de etanol, $0,5 \mathrm{~mL}$ de $250 \mu \mathrm{M}$ de solução etanólica de $\mathrm{DPPH}^{*}$ e $50 \mu \mathrm{L}$ de diferentes concentrações de AF padrão ou AF-GM. Os tubos foram mantidos a temperatura ambiente por 10 min e a absorvância foi lida a $517 \mathrm{~nm}$. O controle positivo não continha $\mathrm{AF}$ e o branco foi constituído de $1 \mathrm{~mL}$ de tampão acetato $100 \mathrm{mM}, \mathrm{pH} 5,5$ e $1,5 \mathrm{~mL}$ de etanol. A atividade antioxidante foi expressa como \% de atividade doadora de elétrons ao radical DPPH pelo AF e estimada pela seguinte equação:

$\%$ de Atividade antioxidante $=100-\left(100 \mathrm{~A}_{\mathrm{a}} / \mathrm{A}_{0}\right)$

onde $\mathrm{A}_{\mathrm{a}}$ é a absorvância da amostra e $\mathrm{A}_{0}$ é a absorvância do controle positivo.

\section{Ensaio de deoxirribose}

A eficiência do AF no sequestro do radical hidroxil foi avaliada pela degradação de deoxirribose.$^{31}$ Foram misturados em tubos de ensaios $1 \mathrm{~mL}$ de tampão $\mathrm{KH}_{2} \mathrm{PO}_{4}-\mathrm{KOH}(20 \mathrm{mM}, \mathrm{pH} 7,4), 10 \mu \mathrm{L}$ de ascorbato $(100 \mu \mathrm{M}), 50 \mu \mathrm{L}$ de diferentes concentrações de $\mathrm{AF}$ padrão ou AF-GM, $10 \mu \mathrm{L}$ de deoxirribose $(2,8 \mathrm{mM}), 10 \mu \mathrm{L}$ de $\mathrm{H}_{2} \mathrm{O}_{2}(1 \mathrm{mM})$, $10 \mu \mathrm{L}$ de Fe-EDTA $\left(\mathrm{FeCl}_{3} 50 \mu \mathrm{M}\right.$, EDTA $\left.52 \mu \mathrm{M}\right)$. Os tubos, contendo a mistura de reação, foram incubados a $37^{\circ} \mathrm{C}$ por $30 \mathrm{~min}$. Após este período, $1 \mathrm{~mL}$ de ácido tiobarbitúrico (1\% em NaOH $50 \mathrm{mM}), 100$ $\mu \mathrm{L}$ de $\mathrm{NaOH}(10 \mathrm{M})$ e $500 \mu \mathrm{L}$ de $\mathrm{H}_{3} \mathrm{PO}_{4}(20 \%)$ foram adicionados aos tubos e os mesmos foram incubados a $85^{\circ} \mathrm{C}$ por $20 \mathrm{~min}$. No ensaio, ocorreram as seguintes reações:

$\mathrm{Fe}^{3+}$ - EDTA + ascorbato $\rightarrow \mathrm{Fe}^{2+}$ - EDTA + ascorbato oxidado

$\mathrm{Fe}^{2+}-\mathrm{EDTA}+\mathrm{H}_{2} \mathrm{O}_{2} \rightarrow \mathrm{OH}^{-}+{ }^{\circ} \mathrm{OH}+\mathrm{Fe}^{3+}-\mathrm{EDTA}$

$\cdot \mathrm{OH}+$ deoxirribose $\rightarrow$ fragmentos $\rightarrow$ MDA
$2 \mathrm{TBA}+\mathrm{MDA} \rightarrow$ cromóforo róseo

A formação de substâncias reativas ao ácido tiobarbitúrico foi avaliada, principalmente, como MDA devido à degradação de deoxirribose causada pelo radical hidroxil. A medida foi realizada em 535 $\mathrm{nm}$ a temperatura ambiente. Foram feitos concomitantemente o branco (ausência de deoxirribose) e o controle positivo (ausência de AF). Assim, a atividade antioxidante foi expressa como \% de sequestro do radical hidroxil pelo AF e estimada similarmente à Equação 1.

\section{Ensaio de batofenantrolina}

A atividade queladora do íon $\mathrm{Fe}^{2+}$ pelo $\mathrm{AF}$ foi determinada com o ensaio de batofenantrolina (BPS). ${ }^{27}$ Neste ensaio, $10 \mu \mathrm{L}$ de $\left(\mathrm{NH}_{4}\right)_{2} \mathrm{Fe}\left(\mathrm{SO}_{4}\right)_{2}(50 \mu \mathrm{M}), 50 \mu \mathrm{L}$ das diferentes concentrações de $\mathrm{AF}$ padrão ou AF-GM e $10 \mu \mathrm{L}$ de $\operatorname{BPS}(0,2 \mathrm{mM})$ foram adicionados a 2 $\mathrm{mL}$ de meio de reação contendo $125 \mathrm{mM}$ de sacarose, $65 \mathrm{mM}$ de $\mathrm{KCl}$ e $10 \mathrm{mM}$ de Tris- $\mathrm{HCl}, \mathrm{pH} 7,4$. $\mathrm{O} \mathrm{Fe}^{2+}$ e AF foram mantidos em contato por $0,5,10$ ou 15 min no meio de reação antes da adição de BPS. Após adição dos reagentes, os tubos contendo a mistura de reação foram mantidos a temperatura ambiente por $15 \mathrm{~min}$. A atividade queladora do ferro foi determinada pela formação do complexo $\mathrm{Fe}_{2}(\mathrm{BPS})_{3}$.

A coloração proveniente da reação foi lida em $530 \mathrm{~nm}$. Foram feitos concomitantemente o branco (meio de reação) e o controle positivo (meio de reação $+\mathrm{Fe}^{2+}+\mathrm{BPS}$ ). A atividade antioxidante foi expressa como \% de atividade queladora do íon $\mathrm{Fe}^{2+}$ pelo $\mathrm{AF}$ e estimada similarmente à Equação 1 .

\section{Análises estatísticas}

Para avaliar a influência do tempo no ensaio de batofenantrolina os dados foram estatisticamente analisados utilizando-se a ANOVA de uma via seguida do teste-t de comparações múltiplas de Bonferroni (Programa GraphPad Prism, Versão 4.00, 2003). Os resultados foram expressos como média \pm desvio padrão da média (SEM) e considerado significativamente diferente quando foi obtido $\mathrm{P}<0,05$.

\section{RESULTADOS E DISCUSSÃO}

\section{Precisão dos métodos analíticos}

A precisão do ensaio de deoxirribose foi avaliada e os coeficientes de variação (CV) intraensaios foram de 8,6 a $9,1 \%$ para concentração de $6,6 \mu \mathrm{M}$ e 6,9 a $10,1 \%$ para concentração de $66,5 \mu \mathrm{M}$ de AF padrão. Os coeficientes de variação interensaio, para 14 determinações, foram de 1,2 e 3,7\%, respectivamente para as concentrações de 6,6 e 66,5 $\mu \mathrm{M}$ de AF padrão. Assim, o ensaio de deoxirribose apresentou uma ótima precisão nas concentrações de 6,6 e 66,5 $\mu \mathrm{M}$ de AF padrão.

A precisão do ensaio utilizando a BPS também foi avaliada e os coeficientes de variação intraensaios variaram de 2,1 a 2,7\% para concentração de $3,3 \mu \mathrm{M}$ e de 1,7 a $1,8 \%$ para a concentração de $6,6 \mu \mathrm{M}$ de AF padrão. Os coeficientes de variação interensaio para as concentrações de $3,3 \mu \mathrm{M}$ de 10 determinações e de $6,6 \mu \mathrm{M}$ de 11 determinações foram, respectivamente, de 7,6 e 1,1\%. Segundo ANVISA e pesquisadores, o CV menor do que $15 \%$ indica que o método apresenta uma boa precisão..$^{37,38}$

\section{Avaliação da atividade doadora de elétrons pelo $\mathrm{AF}$ ao radical estável DPPH*}

Neste ensaio, não foi possível a obtenção de resultado satisfatório para a avaliação da atividade antioxidante do AF. Embora o método seja simples e propicie resultados rápidos quando comparado com 
outros ensaios, foi observado que o AF não apresentou capacidade de doação de elétrons ao $\mathrm{DPPH}^{*}$ (2,2-difenil-1-picril-hidrazil), confirmando a sua ação quelante.

\section{Avaliação da atividade sequestradora do AF sobre o radical hidroxil pelo ensaio de deoxirribose}

O ensaio de deoxirribose foi utilizado para verificar se o AF é eficiente no sequestro de radicais hidroxil. Na Figura 1A, observa-se que o AF padrão apresentou atividade antioxidante máxima de 18,2\% a partir da concentração de 33,2 $\mu \mathrm{M}$. Entretanto, na Figura 1B, o AFGM apresentou atividade antioxidante máxima de 29,3\% a partir da concentração de 130,5 $\mu \mathrm{M}$. Comparando a atividade antioxidante do AF padrão e AF-GM, nas mesmas concentrações, ou seja, de 33,2 $\mu \mathrm{M}$, observa-se que o AF-GM apresentou atividade antioxidante de $18,1 \%$ e similar à do AF padrão. Como a atividade antioxidante máxima do AF-GM foi maior que a do $\mathrm{AF}$ padrão, esta diferença pode estar associada ao possível teor de IP6 no AF-GM. O AF (IP6) pode ser hidrolisado quimicamente ou por fitases formando o IP5, IP4, IP3 e, possivelmente, inositol di- e monofosfato durante estocagem, fermentação, germinação ou processamento. ${ }^{18,39,40}$ Entretanto, somente o IP6 e IP5 possuem atividade quelante e apresentam capacidade de afetar a biodisponibilidade de minerais de forma significativa. ${ }^{41}$ Além disso, o IP5 ${ }^{40}$ geralmente apresenta uma ação sinérgica com o IP6, aumentando sua capacidade antioxidante.
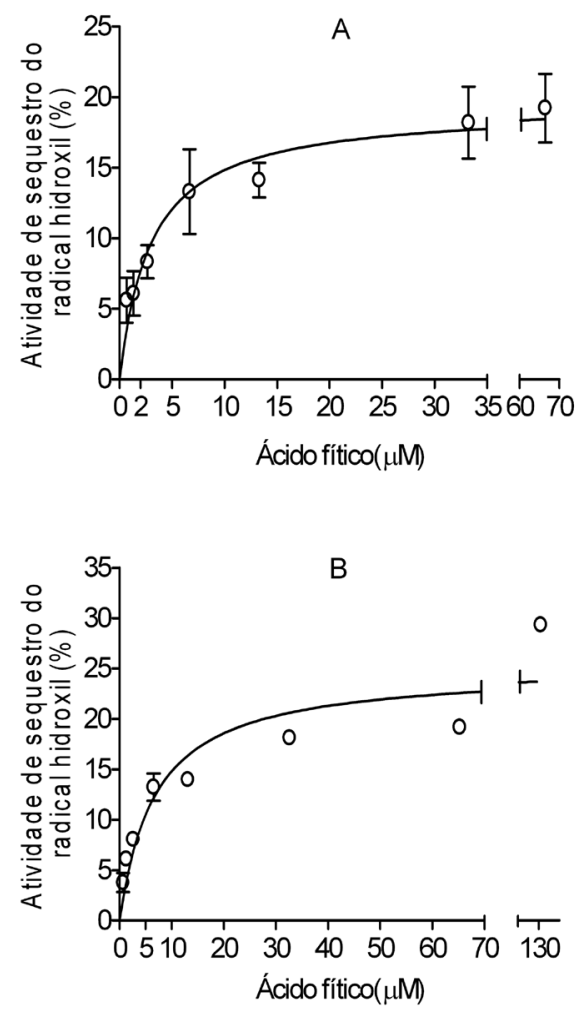

Figura 1. (A) Atividade de sequestro do radical hidroxil pelo ácido fítico padrão por meio de ensaio de deoxirribose. Resultados expressos como média \pm SEM. (B) Atividade de sequestro do radical hidroxil pelo ácido fítico do germe de milho por meio de ensaio de deoxirribose. Resultados expressos como média \pm SEM

A outra possível diferença na atividade antioxidante seria a presença de outras substâncias no AF-GM que poderiam afetar o sequestro do radical hidroxil. O radical hidroxil é altamente reativo com meia vida nas células estimada em somente $10^{-9} \mathrm{~s}$. Uma das características do radical hidroxil é a formação de outras espécies de radicais que são menos reativos e, quando em contato, reage com todas proteínas, DNA, ácidos graxos poli-insaturados das membranas e quase todas moléculas biológicas. ${ }^{42}$ Quando um antioxidante interfere com danos causados pelo radical hidroxil, geralmente não atuará somente pelo sequestro do radical, mas pelo sequestro ou bloqueio dos precursores de sua formação (ânion superóxido, peróxido de hidrogênio) e/ou pela quelação de íons metais de transição. ${ }^{43}$ Portanto, uma substância poderá apresentar um potencial contra o radical hidroxil in vivo devido a atividades sequestradora de radical e queladora de íon ferro, como confirmado nesta investigação com os ensaios de deoxirribose e de batofenantrolina.

\section{Avaliação da atividade queladora do íon ferro pelo AF utilizando a batofenantrolina (BPS)}

A atividade queladora do íon ferro pelo AF utilizando o ensaio de BPS foi também utilizada para avaliar o potencial antioxidante do AF padrão e AF-GM. As Figuras 2 e 3 mostram o efeito de diferentes concentrações do AF padrão e AF-GM e tempos de contato com o ferro para formação do complexo $\mathrm{Fe}^{2+} \mathrm{e} \mathrm{AF}$ antes da adição da BPS. $\mathrm{A}$ atividade queladora do íon $\mathrm{Fe}^{2+}$ pelo $\mathrm{AF}$ padrão foi dependente significativamente da concentração, ou seja, a atividade queladora do íon $\mathrm{Fe}^{2+}$ aumentou com elevação da concentração de 1,3 a 6,6 $\mu \mathrm{M}$ do AF padrão (Figura 2). O mesmo foi observado com o AF-GM, porém o tempo de contato do AF-GM com o ferro afetou significativamente a sua atividade queladora do íon $\mathrm{Fe}^{2+}$ (Figura 3). Na concentração de 6,6 $\mu \mathrm{M}$ de AF padrão, após 15 min de adição de BPS, foi observada (Figura 2) uma atividade queladora de $\mathrm{Fe}^{2+}$ de aproximadamente $70 \%$, enquanto que para o AF-GM, na mesma concentração (Figura 3), a atividade queladora foi de $33 \%$.

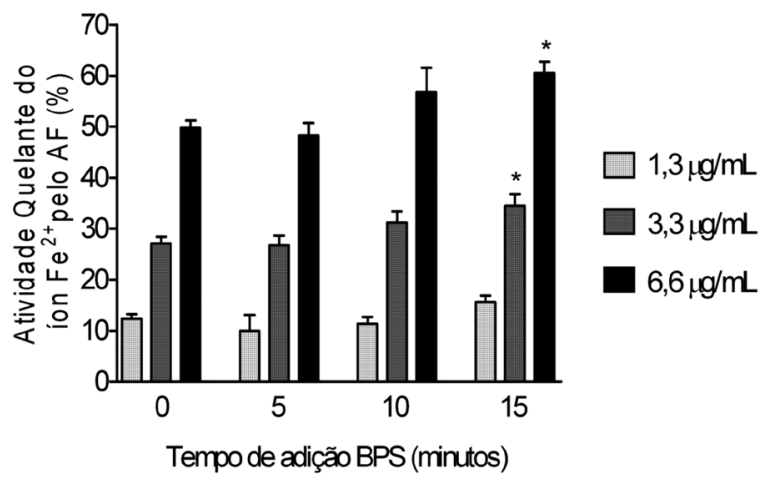

Figura 2. Atividade quelante do íon ferro pelo ácido fítico padrão, em diferentes concentrações. Resultados são representados pela média \pm SEM. * diferença estatística significativa em relação à BPS adicionada imediatamente $(P<0,05)$

Neste ensaio, os resultados confirmam o potencial do AF em quelar íons ferro (Figuras 2 e 3). Porém, foi observada uma maior afinidade entre o $\mathrm{Fe}^{2+}$ e BPS do que $\mathrm{Fe}^{2+}$ e $\mathrm{AF}$, pois quando o $\mathrm{AF}$ e BPS são adicionados simultaneamente no meio de reação, ou seja, tempo 0, ocorreu uma baixa atividade queladora do íon $\mathrm{Fe}^{2+} \mathrm{e}$ quando em contato prévio de 5, 10 ou 15 min entre o $\mathrm{Fe}^{2+}$ e AF-GM, antes da adição de BPS, a atividade queladora do íon $\mathrm{Fe}^{2+}$ aumentou significativamente (Figura 3). Assim, o tempo de contato de $15 \mathrm{~min}$ foi estabelecido para verificar o efeito de diferentes concentrações de AF padrão e AF-GM na atividade queladora do íon $\mathrm{Fe}^{2+}$ (Figura 4). Observa-se na Figura 4A, que a máxima atividade foi de $98,2 \%$ de quelação do íon $\mathrm{Fe}^{2+}$ na concentração de $16,6 \mu \mathrm{M}$ de $\mathrm{AF}$ padrão. Entretanto, para o AF-GM a mesma atividade máxima foi alcançada 


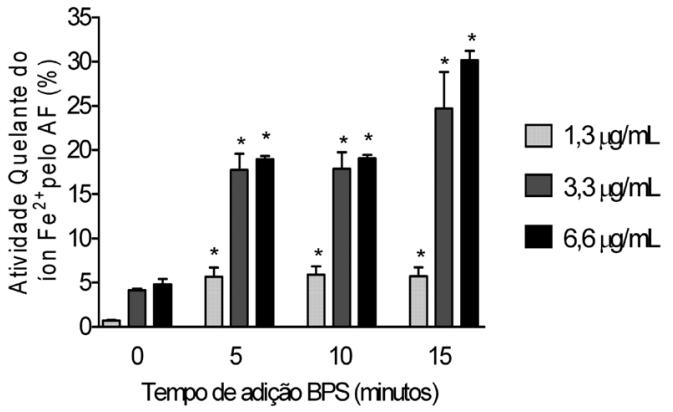

Figura 3. Atividade quelante do ín ferro pelo ácido fítico do germe de milho, em diferentes concentrações. Resultados são representados pela média \pm SEM. * diferença estatística significativa em relação à BPS adicionada imediatamente $(P<0,05)$
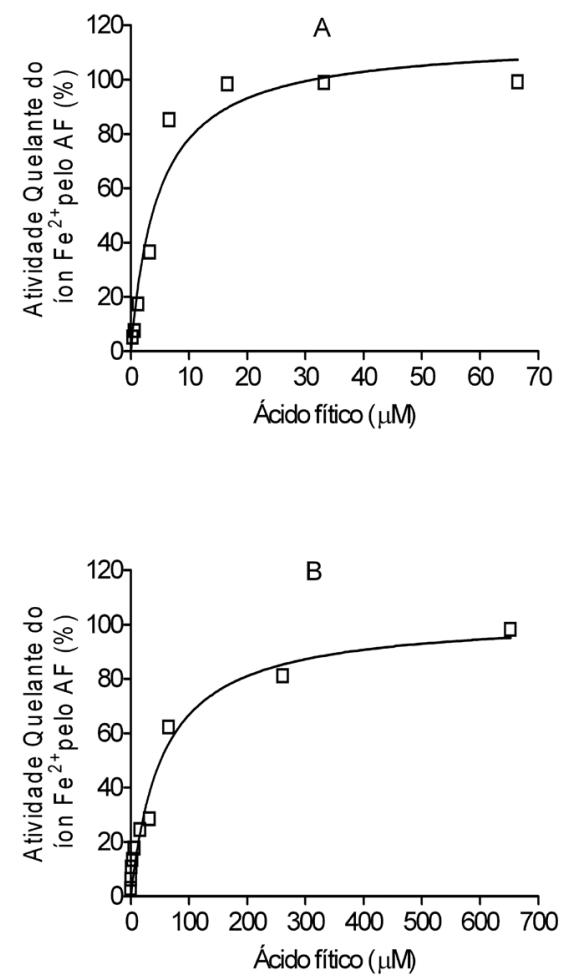

Figura 4. (A) Atividade quelante do íon ferro pelo ácido fítico padrão por meio de ensaio de batofenantrolina. Resultados expressos como média \pm SEM. (B) Atividade quelante do ín ferro pelo ácido fítico do germe de milho por meio de ensaio de batofenantrolina. Resultados expressos como média \pm SEM

na concentração de 652,7 $\mu \mathrm{M}$ (Figura 4B). Estes resultados demonstraram que o $\mathrm{AF}$ padrão apresentou uma maior atividade de quelação de íons $\mathrm{Fe}^{2+}$, quando comparado com o AF-GM.

Embora haja evidências de que a atividade antioxidante do AF depende da quelação do íon $\mathrm{Fe}^{2+}$, o mecanismo de interação entre o $\mathrm{AF}$ e minerais ainda não está totalmente esclarecido. ${ }^{44} \mathrm{O}$ AF é descrito como um forte quelador de íons $\mathrm{Fe}^{2+}$ e possivelmente mantém todo o ferro na forma oxidada prevenindo, assim, a formação de hidroperóxidos lipídicos e, consequentemente, a peroxidação lipídica. ${ }^{45} \mathrm{O}$ AF pode também inibir a formação de aroma de requentado ou warmed-over flavor (WOF) em produtos alimentícios, devido à formação de quelatos de ferro inativos cataliticamente. ${ }^{10}$ Para o desenvolvimento de WOF em carnes cozidas, os fosfolipídios e os triglicerídios em menor proporção, foram apontados como os principais responsáveis. ${ }^{46}$ Os íons $\mathrm{Fe}^{2+}$ que catalisam a formação de WOF em carnes são provenientes da mioglobina que, nos processos de cozimento e trituração, é parcialmente destruída liberando $\mathrm{Fe}^{2+}{ }^{27}$ Esta habilidade de formação de quelatos de ferro permite ao AF ser mais efetivo na inibição de WOF quando comparado a outros agentes quelantes. ${ }^{10}$ De 12 tipos de agentes quelantes de ferro avaliados, o AF foi o que apresentou maior atividade quelante na inibição de danos oxidativos em sistemas biológicos. ${ }^{15}$ Além disso, já foi descrito ${ }^{8}$ que o AF exerce maior propriedade antioxidante devido a sua afinidade relativamente elevada pelo ferro. A capacidade de quelação de íons $\mathrm{Fe}^{+2}$ pelo $\mathrm{AF}$ pode ser fundamental em outros mecanismos do sistema de defesa antioxidante, influenciando também na atividade de enzimas em reações oxidativas. ${ }^{9}$

\section{CONCLUSÃO}

O AF-GM apresentou potencial antioxidante confirmado pela atividade de sequestro de radicais livres e quelação de metais, por meio de ensaios de deoxirribose e batofenantrolina. A atividade de sequestro do radical hidroxil foi dependente da concentração de AF-GM. A atividade quelante para o $\mathrm{Fe}^{+2}$ aumentou com elevação da concentração do AF-GM e com o tempo de contato com o $\mathrm{Fe}^{+2}$.

\section{AGRADECIMENTOS}

À CAPES pela concessão de bolsa de doutorado e CNPq pelo apoio financeiro.

\section{REFERÊNCIAS}

1. Cheryan, M.; CRC Crit. Rev. Food Sci. Nutr. 1980,13, 297.

2. Erdman, J. W.; J. Am. Oil Chem. Soc. 1979, 56, 736.

3. Leal, E. S.; Dissertação de Mestrado, Universidade Estadual de Londrina, Brasil, 2000.

4. Nogueira, R. B.; Tese de Doutorado, Universidade Estadual de Londrina, Brasil, 2004

5. Reddy, N. R.; Sathe, S. K.; Salunkhe, D. K.; Adv. Food Res. 1982, $28,1$.

6. Tsao, G. T.; Zheng, Y.; Lu, J.; Appl. Biochem. Biotechnol. 1997, 63, 731.

7. Vohra, P.; Gray, G. A.; Kratzer, F. H.; Proc. Soc. Exp. Biol. Med. 1965, $120,447$.

8. Graf, E.; Eaton, J. W.; Free Radical Biol. Med. 1990, 8, 61.

9. Conforth, D. P. Em Food phytates; Reddy, N. R.; Sathe, S. K., eds.; 2002.

10. Empson, K. L.; Labuza, T. P.; Graf, E.; J. Food Sci. 1991, 56, 560.

11. Barreto, A. C. S.; International Congress of Meat Science and Technology 1996, vol. 42, p. 119.

12. Lee, B. J.; Hendricks, D. G.; J. Food Sci. 1995, 60, 241.

13. Ghiretti, G. P.; Zanardi, E.; Novelli, E.; Campanini, G.; Dazzi, G.; Madarena, G.; Chizzolini, R.; Meat Sci. 1997, 47,167.

14. Graf, E.; Eaton, J. W.; J. Nutr. 1984, 114, 1192.

15. Graf, E.; Mahoney, J. R.; Bryant, R. G.; Eaton, J. W.; J. Biol. Chem. 1984, 259, 3620.

16. Graf, E.; Empson, K. 1.; Eaton, J. W.; J. Biol. Chem. 1987, 262, 11647.

17. Persson, H.; Tûrk, M.; Nyman, M.; Sandberg, A. S.; J. Agric. Food Chem. 1998, 46, 3194.

18. Oatway, L.; Vasanthan, T.; Helm, J. H.; Food Rev. Int. 2001, 17, 419.

19. Graf, E.; J. Am. Oil Chem. Soc. 1983, 60, 11.

20. Hix, D. K.; Klopfenstein, C. F.; Walker, C. E.; Cereal Chem. 1997, 74, 281.

21. Pokorny, J.; Yanishlieva, N.; Gordon, M.; Antioxidants in food, Washington, 2003. 
22. Soares, A. L.; Olivo, R.; Shimokomaki, M.; Ida, E. I.; Brazilian Arch Biol. Technol. 2004, 47, 57.

23. Harbach, A. P. R.; Costa, M. C. R.; Soares, A. L.; Bridi, A. M.; Shimokomaki, M.; Silva, C. A.; Ida, E. I.; Food Chem. 2007, 100, 1630.

24. Stodolak, B.; Starzynska, A.; Czyszczon, M.; Zyla, K.; Food Chem. 2007, 101, 1041 .

25. Berg, R. V. D.; Haenen, G. R. M. M.; Berg, H. V. D.; Bast, A.; Food Chem. 1999, 66, 511.

26. Prior, R. L.; Wu, X.; Schaich, K.; J. Agric. Food Chem. 2005, 53, 4290.

27. Bolanm, B. J.; Ulvik, R. J.; Biochem. J. 1987, 243, 55.

28. Silva, M. M.; Santos, M. R.; Caroço, G.; Rocha, R.; Justino, G.; Mira, L.; Free Radical Res. 2002, 36, 1219.

29. Ahn, H. J.; Kim, J. H.; Jo, C.; Kim, M. J.; Byun, M. W.; Food Chem. 2004, 88,173.

30. Aruoma, O. I.; Methods Enzymol. 1994, 233, 57.

31. Halliwell, B.; Gutteridge, J. M. C.; Aruoma, O. I.; Anal. Biochem. 1987, $165,215$.

32. Marquele, F. D.; Di Mambro, V. M.; Georgetti, S. R.; Casagrande, R.; Valim, Y. M. L.; Fonseca, M. J. V.; J. Pharm. Biomed. 2005, 39, 455.

33. Fukuji, T. S.; Ferreira, D. L.; Soares, A. L.; Prete, C. E. C.; Ida, E. I.; Acta Sci. Agro. 2008, 30, 31.
34. Latta, M.; Eskin, M.; J. Agric. Food Chem. 1980, 28, 1313.

35. Ellis, R.; Morris, E. R.; Cereal Chem. 1986, 63, 58.

36. Blois, M. S.; Nature 1958, 181, 1199.

37. Brasil, Agência Nacional de Vigilância Sanitária - ANVISA; Resolução RE no 899, 2003.

38. Ribani, M.; Bottoli, C. B. G.; Collins, C. H.; Jardim, I. C. S. F.; Melo, L. F. C.; Quim. Nova 2004, 27, 771.

39. Burbano, C.; Muzquiz, M.; Osagie, A.; Ayet, G.; Cuadrado, C.; Food Chem. 1995, 52, 321.

40. Plaami, S.; Lebensm.Wiss.Technol. 1997, 30, 633.

41. Sandberg, A. S.; Carlsson, N. G.; Svanberg, U.; J. Food Sci. 1989, 54, 159.

42. Aruoma, O. I.; Asia - Pac. J. Clin. Nutr. 1999, 8, 53.

43. Halliwell, B.; Aeschbach, R.; Löliger, J.; Aruoma, O. I.; Food Chem. Toxicol. 1995, 33, 601.

44. Febles, C. I.; Arias, A.; Hardisson, A.; Rodriguez-Alvarez, C.; Sierra, A.; Food Chem. 2001, 74, 437.

45. Phillippy, B. Q.; Graf, E.; Free Radical Biol. Med. 1997, 22, 939.

46. Igene, J. O.; Pearson, A. M.; J. Food Sci. 1979, 44, 1285.

47. Gray, J. I.; Pearson, A. M.; Adv. Food Res. 1984, 29, 1. 